\title{
A CASE OF NON-PALPABLE, MULTIFOCAL, HETEROGENEOUS LEFT BREAST CARCINOMA WITH MAMMOGRAPHIC PRESENTATION OF CLUSTERED MULTIPLE MICROCALCIFICATIONS
}

\author{
Vasil D. NANEV ${ }^{1}$, Liana G. TONEVA ${ }^{2}$, Angel D. YORDANOV ${ }^{3}$, Strahil A. STRASHILOV ${ }^{\bowtie}$, \\ Ivan N. IVANOV ${ }^{5}$
}

${ }^{1}$ Department of Surgical Oncology, University Hospital „Dr. Georgi Stranski“, Medical University Pleven, Pleven, Bulgaria

${ }^{2}$ Department of Radiology, University Hospital „Dr. Georgi Stranski“, Medical University Pleven, Pleven, Bulgaria

${ }^{3}$ Clinic of Gynecologic Oncology, University Hospital „Dr. Georgi Stranski“, Medical University Pleven, Pleven, Bulgaria

${ }^{4}$ Department of Plastic Restorative, Reconstructive and Aesthetic Surgery, University Hospital „Dr. Georgi Stranski“, Medical University Pleven, Pleven, Bulgaria

${ }^{5}$ Department of Clinical Pathology, University Hospital „Dr. Georgi Stranski“, Medical University Pleven, Pleven, Bulgaria

Received 10 June 2020, Accepted 07 Aug 2020

hitps://doi.org/10.31688/ABMU.2020.55.3.15

\begin{abstract}
Introduction. In 2018, the number of newly diagnosed breast carcinomas in the 28 countries of the European Union was 404 920, with an estimated annual incidence of 144.9/100 000. Figures have increased since the introduction of mammography screening and continue to rise with population aging. Mammograms may convey clinically occult breast cancer, which is associated in some cases with the presence of clustered microcalcifications.
\end{abstract}

Case presentation. We present the case of a 64-year-old patient with multifocal invasive ductal left

\section{Résumé}

Un cas de carcinome du sein gauche hétérogène multifocal non palpable avec présentation mammographique de microcalcifications multiples agrégées

Introduction. En 2018, le nombre de cancers du sein nouvellement diagnostiqués dans les 28 pays de l'Union européenne était de 404 920, avec une incidence annuelle estimée à 144,9/100 000. Les chiffres ont augmenté depuis l'introduction du dépistage par mammographie et continuent d'augmenter avec le vieillissement de la population. Les mammographies 
breast cancer and lobular carcinoma in situ, diagnosed after biopsy of a mammogram-marked area with clustered microcalcifications. The patient underwent subsequent radical surgical treatment.

Conclusions. Clustered microcalcifications on mammograms may indicate clinically occult breast cancer. These lesions cause clinical and diagnostic difficulties due to the inability of ultrasound visualisation and the option to perform punch biopsy, as recommended by European Society for Medical Oncology. Excision biopsy by mammography-guided wire marking and pathological-anatomical examination of the entire resectate can detect tumour heterogeneity, which is important for the subsequent therapeutic strategy and prognosis of the disease.

Keywords: clustered microcalcifications, mammography-guided metallic marker, heterogeneity of mammary gland tumour.

\author{
List of abbreviations: \\ LCNB - large-core needle biopsy \\ FNAB - fine needle aspiration biopsy \\ ESMO - European Society for Medical Oncology \\ LMG - left mammary gland \\ DCIS - intraductal carcinoma \\ LCIS - lobular carcinoma in situ
}

\section{INTRODUCTION}

In 2018, the number of newly diagnosed breast cancer cases in the 28 European Union (EU) countries was 404,920, with an estimated annual incidence of 144.9/100 $000^{1}$. In Bulgaria, the incidence in 2018 was $98.8 / 100000$ or $26.9 \%$ of all newly registered women with cancer ${ }^{1}$. Incidence rates have increased since the introduction of mammography screening and continue to rise with population aging. In recent years, mortality has declined in most Western countries, due to improved treatment and earlier detection $^{2}$. Large-core needle biopsy (LCNB), or, if not possible, fine needle aspiration biopsy (FNAB), are recommended by the European Society for Medical Oncology (ESMO) Clinical Practice Guidelines on Breast Cancer, for pathological diagnosis of breast cancer. Excision biopsy is an option when 'repeated' main biopsy methods (FNAB or punch) have failed to diagnose the tumour ${ }^{3}$. Ultrasound-guided biopsy is recommended if the lesion is non-palpable 4 . However, there is a small group of lesions difficult for ultrasound detection, causing clinical and diagnostic challenges. peuvent signaler un cancer du sein cliniquement occulte, associé dans certains cas à la présence de microcalcifications en grappes.

Présentation du cas. Nous présentons le cas d'une patiente de 64 ans atteinte d'un cancer du sein gauche canalaire invasif multifocal et d'un carcinome lobulaire diagnostiqué in situ après biopsie d'une zone marquée par mammographie avec des microcalcifications en grappes. Le patient a subi un traitement chirurgical radical ultérieur.

Conclusion. Les microcalcifications groupées sur les mammographies peuvent indiquer un cancer du sein cliniquement occulte. Ces lésions entraînent des difficultés cliniques et diagnostiques en raison de l'impossibilité de visualiser par les ultrasons et de l'option d'effectuer une biopsie par ponction selon la recommandation de la Société Européenne d'Oncologie Médicale. La biopsie d'excision par marquage au fil guidé par mammographie et l'examen anatomo-pathologique de la zone réséquée peuvent détecter une hétérogénéité tumorale qui est importante pour la stratégie thérapeutique et le pronostic de la maladie.

Mots-clés: microcalcifications groupées, marqueur métallique guidé par mammographie, hétérogénéité de la tumeur de la glande mammaire.

\section{Case presentation}

We present the case of a 64-year-old female patient, with an asymptomatic non-palpable left breast cancer. The patient has signed an informed consent prior to performing any diagnostic or treatment procedures.

In December 2018, a screening mammography was performed, which showed clustered microcalcifications in the upper lateral quadrant of the left mammary gland (Fig. 1). The patient did not undertake any further diagnostic procedures. Repeated mammogram was performed in September 2019, after clinical examination. Clusters of granular microcalcifications were described in the upper outer quadrant of the left mammary gland, increased in number and density, compared to the mammogram of December 2018 (Fig. 2). The finding was classified as BI-RADS 4c, highly suspected of malignancy $>50$ to $95 \%$. The patient was hospitalised in a surgical clinic for diagnostic clarification. Physical examination did not detect at palpation solid lesions or increased density in both mammary glands, nor pathologically enlarged axillary lymph nodes. Chest radiography showed no anomalies, and breast ultrasound did not visualize 




Figure 1. Left breast mammography in cranio-cranial (A) and medio-lateral (B) projections showing clustered multiple microcalcifications, performed in December 2018.
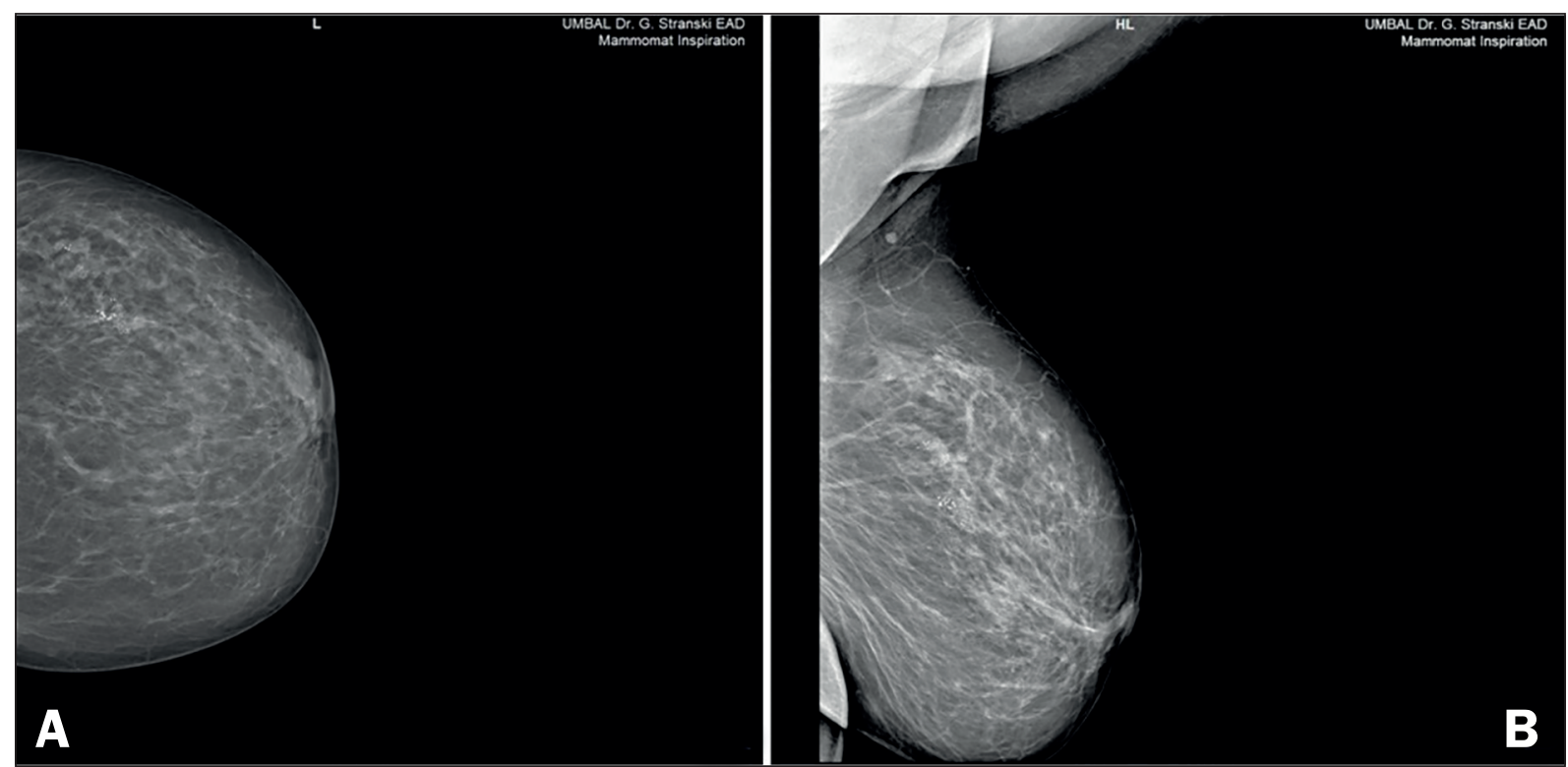

Figure 2. Left breast mammography in cranio-cranial (A) and medio-lateral (B) projections showing clustered multiple microcalcifications, performed in September 2019.

pathological changes corresponding to the ones described at mammography.

Because the lesion was non-palpable and visible at mammography only, preoperative mammography-guided wire marking was performed (Fig. 3). The marked area was resected under general anaesthesia.
Intraoperative X-ray of the resected area with the preoperative wire mark was carried out, to confirm the presence of the marked microcalcifications (Fig. 4).

The specimen was dissected prior to fixation, and numerous small, white, high-density parenchymal inclusions, consistent with the mammographic 


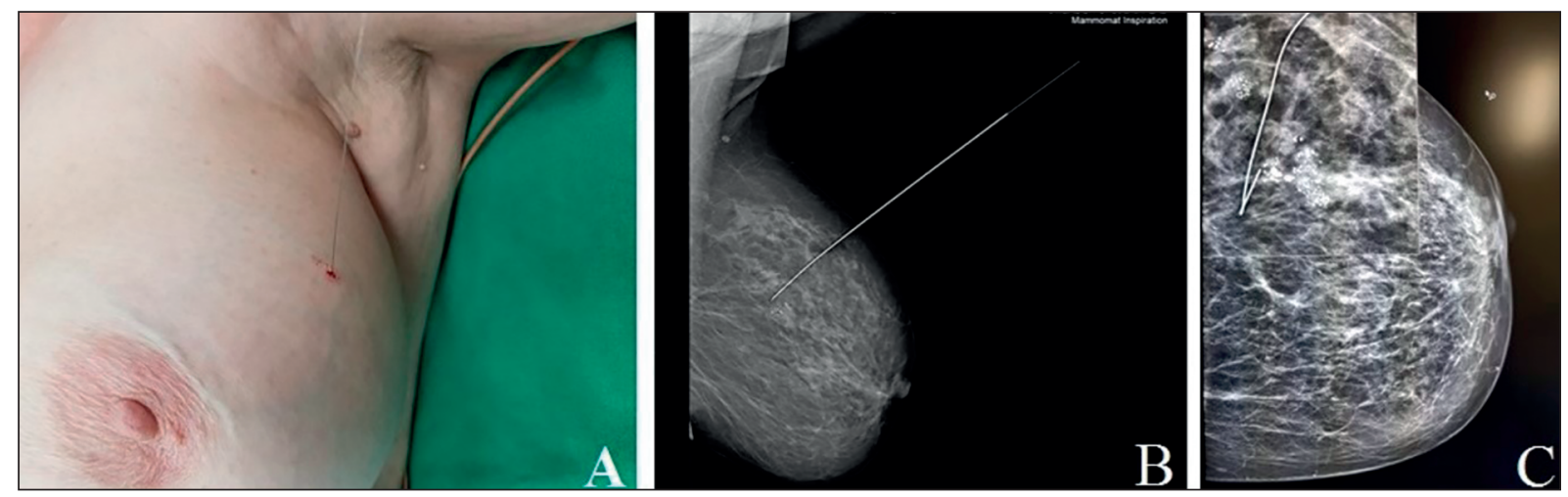

Figure 3. Preoperative mammography-guided wire marking of the left breast.

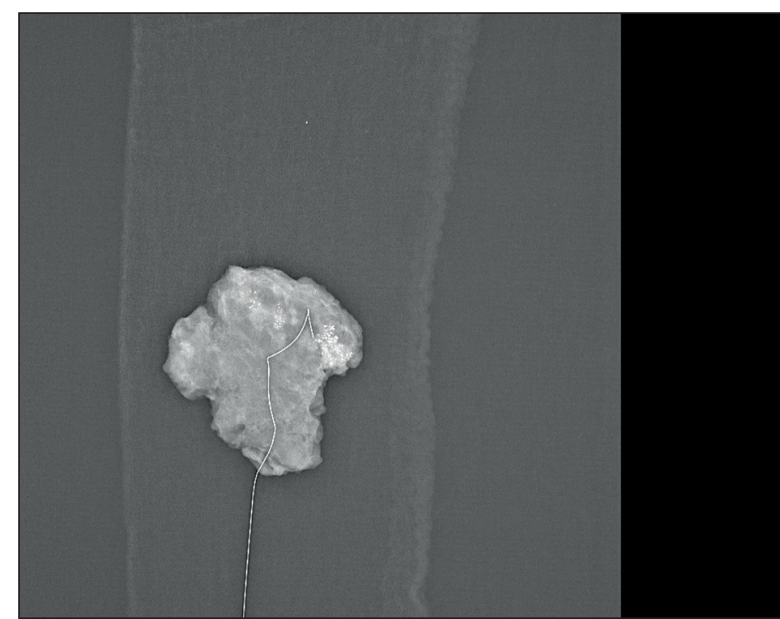

Figure 4. Intraoperative specimen X-ray confirming the presence of the marked microcalcifications.

image, were observed. The fixed specimen was sent to histological examination, along with the completed documentation (Fig. 5). Breast parenchyma with extensive multiple foci of intraductal carcinoma in situ (DCIS) was morphologically identified, carcinoma type G2 with solid and comedonic features, and microcalcifications. Stroma around the segmental ducts was swollen, with fibrotic changes, and the presence of invasive carcinoma. The carcinoma presented by groups of tumour cells around which, after immunohistochemical staining for p63, no myoepithelial layer is detected (ER-0, PR - 0, HER 2 - 2+ Ki 67 40\%). Multifocal invasive carcinoma NST (ductal) carcinoma G2 was morphologically and immunohistochemically established, against a background of extensive DCIS G2 pT1aNxMx. Additional SISH testing showed positive results.

Radical surgical treatment was decided by the Joint Oncology Committee. Mastectomy, because of the presence of diffuse microcalcifications in the remaining parenchyma of the left mammary gland, was performed a month later. Histological results: left breast tumour bed in incomplete organizational

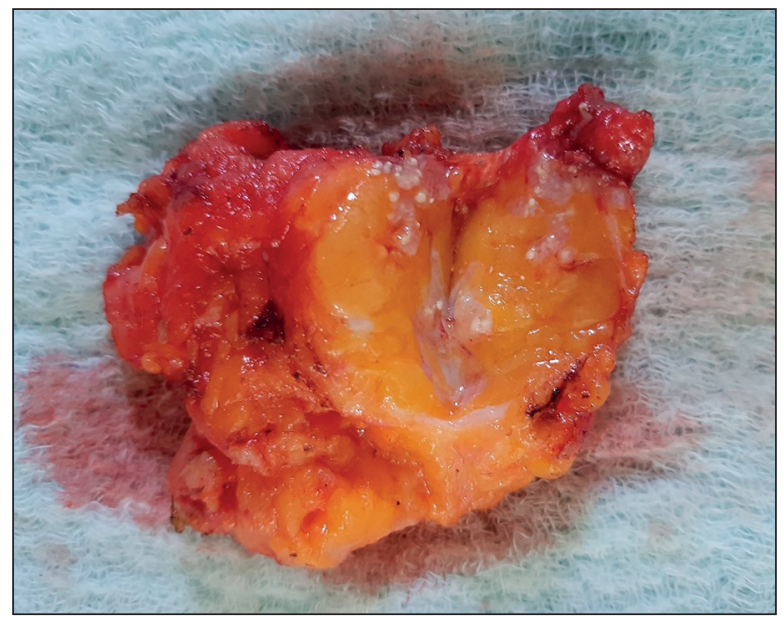

Figure 5. Macroscopic view of the operative specimen with microcalcifications.

process, single terminal channels with lobular carcinoma in situ (LCIS) and lobular cancerization.

Postoperative chemotherapy and targeted therapy were administered. Until the end of May 2020, the patient is still alive and without evidence of local or systemic progression of the breast cancer.

The mammographic presentation of non-palpable, multifocal, heterogeneous breast cancer with clustered multiple microcalcifications is relatively rare and should be well known to avoid gaps in the diagnosis and treatment of this disease.

\section{Discussion}

Mammography may show clinically occult breast carcinoma, which in some cases is associated with presence of cluster microcalcifications. Minimal or no physical manifestation of a breast lesion makes difficult the detection by surgical biopsy $y^{5}$. Stereotactic and vacuum-assisted biopsy established in current practice is not available in all healthcare facilities, due to the need of specific and expensive equipment. 
Mammography-guided metal wire marking localisation of lesions was first described by Dodd et al in $1965^{6}$ and it still remains a choice of biopsy method, providing an internal guide to assist the surgeon during surgical intervention. Mammographic assessment of the resected area is a must prerequisite for the application of this method to confirm the presence of marked preoperative area with microcalcifications. The method is required for classification of clustered microcalcifications on mammograms, classified in our case as BI-RADS 4c. The presence of this type of calcifications (at least five microcalcifications in 1 $\mathrm{cm}^{2}$ ) is a major sign of early stage breast malignancy such as DCIS, but they may also show the presence of invasive cancer, as in our case. Spatial resolution of modern mammography is very high (usually in the range of $40-100 \mu \mathrm{m}$ per pixel) and allows detection of microcalcifications at an early stage ${ }^{7}$, thus contributing to early treatment. This makes it more successful and reduces mortality from the disease ${ }^{8}$.

The age of the patient we presented was 64 years, which is between 5 and 7 years more than the mean age of patients with non-palpable tumour lesions of the breast, described in the studies by Sickles ${ }^{9}$ and Basset et $\mathrm{al}^{10}$. The localization of the non-palpable carcinoma lesions in the upper outer quadrant of the breast and mammographic findings, classified as BI-RADS 4c, in our patient, fully corresponds to the results of Dimitrovska et $\mathrm{al}^{8}$ presented in their study of patients with non-palpable breast lesions.

The presence of two components of malignant breast disease is histologically confirmed in the clinical case presented by us. These are invasive ductal and lobular carcinomas in situ, which reveals tumour heterogeneity. The description of such heterogeneity is rare in the literature. In most of the studies related to non-palpable lesions of the breast, the histological examination of the surgically removed preparation most often showed invasive ductal carcinoma ${ }^{8,10,11}$.

Detection of clustered microcalcifications on a mammogram is the only manifestation, with no clinical picture, which is unusual and rarely described in research literature. This is important for subsequent treatment and prognosis.

\section{Conclusions}

Clustered microcalcifications on mammograms may indicate clinically occult breast cancer. These lesions cause clinical and diagnostic difficulties, because of the inability for ultrasound visualisation and the option to perform punch biopsy, as recommended by ESMO.

Excision biopsy by mammography-guided wire marking and pathological-anatomical examination of the entire resected part can detect tumour heterogeneity, which is important for the subsequent therapeutic strategy and prognosis of the disease.

\section{Author Contributions:}

V.N., L.T., A.Y. and S.S were responsible for the diagnostic procedures, clinical diagnosis, and treatment decisions. I.I. made the histopathological diagnosis, V.N. and S.S. performed the surgery. V.N., A.Y. and S.S wrote the manuscript. All authors have read and agreed to the published version of the manuscript.

\section{Compliance with Ethics Requirements:}

„The authors declare no conflict of interest regarding this article"

"The authors declare that all the procedures and experiments of this study respect the ethical standards in the Helsinki Declaration of 1975, as revised in 2008(5), as well as the national law. Informed consent was obtained from the patient included in the study"

"No funding for this study"

\section{Acknowledgements:}

None

\section{References}

1. ECIS - European Cancer Information System. https://ecis. jrc.ec.europa. eu (accessed on 25 March 2019).

2. Autier P, Boniol M, La Vecchia C, et al. Disparities in breast cancer mortality trends between 30 European countries: retrospective trend analysis of $\mathrm{WHO}$ mortality database. BMJ 2010; 341: c3620.

3. Cardoso F, Kyriakides S, Ohno S, et al. On behalf of the ESMO Guidelines Committee Early breast cancer: ESMO Clinical Practice Guidelines for diagnosis, treatment and follow-up. Annals of Oncology 2019;30:1194-1220.

4. Pritzker K, Nieminen H. Needle biopsy adequacy in the era of precision medicine and value-based health care. Arch Pathol Lab Med. 2019;143:1399-1415

5. Bigongiari LR, Fidler W, Skerker LB, Comstock C, Threatt B. Percutaneous needle localization of breast lesions prior to biopsy: analysis of failures. Clin Radiol. 1977;28(4):419-425.

6. Dodd G, Fry K, Delany W. Pre-op localization of occult carcinoma of the breast. In: Nealon TF, editor. Management of the patient with cancer. Philadelphia: Saunders; 1965. $88-113$

7. Chen Z, Strange H, Denton E, Zwiggelaar R. Analysis of mammographic microcalcification clusters using topological features. In: Fujita H, Hara T, Muramatsu C. (eds) Breast Imaging. IWDM 2014. Lecture Notes in Computer Science, vol 8539. Springer, Cham.

8. Dimitrovska M, Mitreska N, Lazareska M, Jovanovska E, Dodevski A, Stojkoski A. Hook wire localization procedure and early detection of breast cancer - our experience. Open Access Macedonian Journal of Medical Sciences. 2015; $3(2): 273-277$ 
9. Sickles E. Mammographic features of 300 consecutive non-palpable breast cancers. Am J Roentgenol. 1986;146(4): 661-663.

10. Bassett L, Liu T, Giuliano A, Gold R. The prevalence of carcinoma in palpable vs impalpable, mammographically detected lesions. Am J Roentgenol. 1991;157(1):21-24.
11. Schwartz G, Feig S, Rosenberg A, Patchefsky A, Shaber G. Localization and significance of clinically occult breast lesions:experience with 469 needle-guided biopsies. Recent Results Cancer Res. 1984;90:125-132. 